NBER WORKING PAPER SERIES

\title{
DE FACTO OR DE JURE? ETHNIC DIFFERENCES IN QUIT RESPONSES TO LEGAL PROTECTIONS OF MEDICAL MARIJUANA DISPENSARIES
}

\author{
Jenny Williams \\ Rosalie Liccardo Pacula \\ Rosanna Smart \\ Working Paper 25555 \\ http://www.nber.org/papers/w25555 \\ NATIONAL BUREAU OF ECONOMIC RESEARCH \\ 1050 Massachusetts Avenue \\ Cambridge, MA 02138 \\ February 2019
}

The authors thank Shannon Ward who set up the data used in this paper. The views expressed herein are those of the authors and do not necessarily reflect the views of the National Bureau of Economic Research.

NBER working papers are circulated for discussion and comment purposes. They have not been peer-reviewed or been subject to the review by the NBER Board of Directors that accompanies official NBER publications.

(C) 2019 by Jenny Williams, Rosalie Liccardo Pacula, and Rosanna Smart. All rights reserved. Short sections of text, not to exceed two paragraphs, may be quoted without explicit permission provided that full credit, including $(\odot$ notice, is given to the source. 
De Facto or De Jure? Ethnic Differences in Quit Responses to Legal Protections of Medical Marijuana Dispensaries

Jenny Williams, Rosalie Liccardo Pacula, and Rosanna Smart

NBER Working Paper No. 25555

February 2019

JEL No. H75,I18,K42

\section{ABSTRACT}

This paper studies the impact of legal medical marijuana markets on the decision to quit marijuana use, distinguishing between de jure legalization, in which dispensaries are legally protected, and de facto legalization, where dispensaries operate in the absence of laws protecting them. Geographic and temporal variation in the presence of de facto and de jure legalized markets serve to identify their impact on quitting. Although we find little robust evidence that quitting by females is impacted by either the presence or protection of retail medical marijuana dispensaries, our results reveal significant, and ethnically differentiated responses by males. Minority males are found to delay quitting in response to legal protection of dispensaries, while white males delay quitting in response to operating dispensaries. This behavior is consistent with racial and ethnic differences in the risks of arrest for simple marijuana offences, particularly for black males.

Jenny Williams

Department of Economics

University of Melbourne VIC 3010

Australia

and IZA

jenny@unimelb.edu.au

Rosalie Liccardo Pacula

RAND Corporation

1776 Main Street

P.O. Box 2138

Santa Monica, CA 90407-2138

and NBER

pacula@rand.org
Rosanna Smart

RAND Corporation

1776 Main Street

Santa Monica, CA 90407

rsmart@rand.org 


\section{Introduction}

The marijuana policy landscape is changing rapidly both in the United States and abroad. Despite a federal prohibition against marijuana in the United States, ten states have passed laws allowing commercial recreational marijuana markets to exist, and the nation's capital, Washington DC, has passed a law legalizing growing and possession for personal use. Several more states are considering similar legal changes either legislatively or through ballot initiatives. The relevance of these state laws is more than just symbolic, as they have encouraged other jurisdictions to do the same, with Uruguay (2013), Jamaica (2015), and most recently Canada (2017) all passing legislation enabling legal recreational marijuana markets (Kilmer and Pacula, 2017).

While there is a clear expectation that legalization will reduce the criminal justice costs of prohibition and the racial disparities in enforcement and incarceration associated with it (Golub et al., 2007; Nguyen and Reuter, 2012; Nicosia et al., 2017), there is considerable speculation about the impact of legal marijuana markets on recreational marijuana use and public health. As it is too early to evaluate the impact of these legal changes on recreational markets, many have tried to infer implications based on the state medical marijuana policy experiments. Substantial attention has been given to impacts of medical marijuana laws on static measures of recreational use, such as prevalence rates and frequency of use (Anderson et al., 2013, 2015; Hasin et al., 2015; Pacula et al., 2015; Wen et al., 2015). This body of work has shown that medical marijuana laws have spill-over effects on recreational markets, increasing adult recreational marijuana use. What remains unclear, however, is the extent to which the increase in marijuana use induced by medical marijuana laws is a result of decreased quitting among adult marijuana users, or an increase in uptake by this group. Distinguishing between impacts on uptake and quitting is necessary for quantifying the full effect of legal marijuana markets. And given the evidence from the tobacco literature, it is unlikely that those making decisions about initiating and those who are deciding whether to quit respond to policies in the same way (DeCicca et al., 2008; Lillard et al., 2013).

This study contributes to the literature in three key ways. First, our analyses extend beyond static measures of marijuana use by examining quitting behavior to demonstrate how the presence of legal markets for marijuana, whether legally protected are not, influences the duration of marijuana use. The duration of marijuana use is an outcome of considerable policy importance because it is long term use that is more strongly associated with adverse health and social impacts, including anxiety and depression, cardiovascular disease, respiratory problems, and reduced educational attainment (Anderson et al., 2013; Hall, 2015; Marie and Zölitz, 2017; McCaffrey et al., 2010; Moore et al., 2007; van Ours and Williams, 2009; Van Ours and Williams, 2011, 2012). ${ }^{1}$

\footnotetext{
${ }^{1}$ The impact of medical marijuana policies on marijuana uptake is also an area that deserves study. We are unable to pursue this issue in this paper because our analysis is based in the NLSY97, a cohort born over the period 1980-84,
} 
Second, we describe how supply-side regulations of medical marijuana laws have evolved to create differential variation in on-the-ground access to retail markets for marijuana (de facto legalization of dispensaries) versus state legal protections for obtaining marijuana through retail channels (de jure legalization of dispensaries). Finally, we are the first to demonstrate the differential impact of de facto and de jure allowances for marijuana dispensaries across different racial/ethnic groups.

To estimate the impact of the medical marijuana retail environment on quitting, we link information on operating medical marijuana dispensaries and laws protecting them to self-reported longitudinal data on marijuana use from the 1997 National Longitudinal Survey of Youth. Geographic and temporal variation in the presence of operating dispensaries and laws protecting dispensaries serve to identify the impacts of these dimensions of the legal marijuana market on quitting behavior. Our results reveal no evidence that either the presence or legal protection of medical marijuana dispensaries impacts the decision to quit marijuana assuming homogeneous treatment effects.

However, a homogeneous treatment effect approach to studying the impact of legalized marijuana markets on quitting may mask important differences across race/ethnicity and gender, driven by differing costs under prohibition (MacCoun et al., 2009). For example, marijuana's criminal status is routinely used to justify searching individuals during a pretextual stop (Kreit, 2016). ${ }^{2}$ This practice is disproportionately applied to blacks and Hispanics, who are in turn disproportionately arrested and convicted for marijuana possession and sales offenses (Golub et al., 2007; Nguyen and Reuter, 2012; Ramchand et al., 2006), with the most pronounced disparities for black males (Ramchand et al., 2006). ${ }^{3}$ The greater risk of arrest under criminalization for minority males suggests that their quitting behavior may be more responsive to legal protection of marijuana markets.

Allowing for heterogenous effects across race/ethnicity and gender reveals important differences in quitting responses to de facto and de jure legal markets for marijuana. Non-Hispanic white males delay quitting in response to the presence of operating retail dispensaries (de facto legalization), black males respond to the legal protection of retail dispensaries (de jure legalization), and Hispanic males delay quitting in response to both. We find little robust evidence that quitting by females responds to either the presence or protection of retail medical marijuana dispensaries. We conclude that the decision to quit using marijuana among men, and therefore the duration of use, is sensitive to whether de facto legal markets are operating. However, it is the legal protection of markets, similar to the protection we are now observing for recreational markets, that will lead to further

and past the age when uptake generally occurs when the relevant marijuana policies are introduced. For example, the NLSY97 cohort are 21-25 when the first law protecting medical marijuana dispensaries is introduced in 2005.

${ }^{2}$ Even if the motivation for police to stop and search an individual is not related to marijuana offenses, and the resulting arrest is not for a marijuana offense, appealing to suspicions about marijuana are sufficient to justify the stop and search.

${ }^{3}$ Differential arrest risk by sex and race/ethnicity has also been documented in the longitudinal data used for the current study (NLSY97), with estimates showing significantly higher cumulative prevalence of arrest by age 18 and by age 23 among males relative to females, and among black males relative to whites males (Brame et al., 2014). 
increases in duration of use for minorities, reflecting the higher costs they faced under prohibition.

The rest of the paper is organized as follows. Section 2 provides background information on the evolution of medical marijuana laws and medical marijuana dispensaries in the United States. Section 3 describes the data used in the empirical analyses and Section 4 outlines the empirical framework for estimating the effects of medical marijuana laws on the marijuana cessation decision. Our results are presented in Section 5, and Section 6 concludes.

\section{Background on Medical Marijuana Laws and Dispensaries}

State medical marijuana laws differ along a variety of dimensions, which have been discussed at length in several prior studies (Bradford and Bradford, 2018; Klieger et al., 2017; Pacula et al., 2015; Pacula and Smart, 2017; Sabia and Nguyen, 2018; Wen et al., 2015). While little is known about the extent to which many of these dimensions are associated with access by recreational users (Pacula et al., 2015; Smart, 2016), those related to dispensaries have received the greatest research attention given their demonstrated association with changes in prices, potency and market size (Anderson et al., 2013; Sevigny et al., 2014; Smart, 2016). Given the clearer conceptual and empirical links between medical marijuana dispensary provisions and the supply of marijuana to both medical and recreational markets, we focus our discussion and empirical analyses on the presence and legal protections of this supply-side aspect of medical marijuana policy.

\subsection{Evolution of Medical Marijuana Laws}

Modern medical marijuana laws (MMLs), which provide explicit legal protections to patients and their caregivers for possession and use of marijuana for specific medical conditions, first emerged in 1996 with the passage of California's medical marijuana ballot initiative (Proposition 215). By 1999, four more states (Oregon, Washington, Alaska, and Maine) had followed suit, passing laws through similar ballot initiatives. These early MMLs provide patients and their caregivers legal protection from state prosecution for possessing and using marijuana for certain medical conditions as specified in the laws, and also protected doctors from legal state sanctions for discussing the medicinal use of marijuana with their patients. ${ }^{4}$ Early state initiatives were purposefully vague regarding an explicit supply source for the marijuana, due to concerns about a response from the federal government which retained its prohibition (Pertwee, 2014). To the extent that any source

\footnotetext{
${ }^{4}$ These MMLs differed from previous state efforts in the mid-1970's and 1980's to provide legal protections for the medicinal use of marijuana by stating that a patient require a doctor's "recommendation" as opposed to "prescription" to qualify for medical marijuana, a semantic distinction designed to protect physicians from federal sanctions, such as revocation of their license to prescribe medicines (Pacula et al., 2002), and hence allow patients to receive state-legal protections for medicinal marijuana use.
} 
of supply was specified in these early laws, they typically allowed for home cultivation by patients and/or their caregivers, not dispensaries or group cultivation cooperatives (Pacula et al., 2002). ${ }^{5}$

The ambiguity of many of these early laws, combined with explicit federal opposition to state efforts toward liberalizing medical marijuana (Claiborne, 1997; Law, 2001; Newbern, 2000; Pertwee, 2014; Tiersky, 1998), created an environment wherein actual legal protections afforded by MMLs may have been unclear to many of the potential actors involved, including physicians, patients, and suppliers. ${ }^{6}$ While dispensaries and group cultivation cooperatives were not provided de jure legal protections under early state MMLs, the statutory language was ambiguous enough in California, Colorado and Montana to effectively permit the de facto operation of largely unregulated large-scale production, and medical marijuana dispensaries soon began to sprout up in these states.

The mid-2000s saw a shift toward MMLs with more precise regulatory language regarding supply sources, but continued threats of federal prosecution and federal raids of medical marijuana production sites remained an impediment to the development of regulated state systems (Mikos, 2009; Vickovic, 2011). Conflict and lawsuits in California regarding the legitimacy of group cooperatives selling through retail outlets led to the passage of S.B. 420 in 2003, which amended California'a initial MML to explicitly allow for cooperative cultivation and sale to members. However, regulatory discretion of these newly protected legal entities was left to local governments, so as to keep the state out of the crosshairs of the Federal government. While New Mexico became the first state to enact a medical marijuana law that established legal provisions for state-licensed dispensaries in its July 2007 initial legislation (S.B. 523), threats of federal prosecution led to significant delays in licensing (Baker, 2007).

In 2009, the uncertainty about the federal government's response to state experimentation with legal medical marijuana was seemingly resolved. Shortly following the inauguration of President Barack Obama, Attorney General Eric Holder issued a statement that federal authorities would cease interfering with medical marijuana dispensaries operating in compliance with state law (Johnson and Lewis, 2009). On October 19, 2009, Deputy Attorney General David Ogden formalized this policy of federal non-enforcement with a memorandum stating that federal prosecutors "should not focus federal resources on individuals who are in clear and unambiguous compliance with existing

\footnotetext{
${ }^{5}$ States that enabled home cultivation typically set a maximum allowable number of plants that could be cultivated (usually three mature plants), in order to reduce the potential risk patients might face if targeted by the federal government. Exceptions are Washington and California. Washington imposed a limit of a 60-day supply, without specifying a maximum number of plants. California was the only state that did not specify any limit (Pacula et al., 2002). In 2000, Hawaii became the first state to enact a medical marijuana law through its state legislature, but it too specified home cultivation with strict limits on the number of plants as the only source of supply.

${ }^{6}$ For instance, the month following California's passage of Proposition 215, then drug-czar Barry McCaffrey and Attorney General Janet Reno issued statements threatening to suspend the licenses of physicians who recommended marijuana to patients and to render their clinics ineligible for Medicare and Medicaid funding (Annas, 1997; Newbern, 2000). While the enforceability of these federal threats was ruled against with the September 2000 decision in Conant v. McCaffrey, the appeals process continued until October 2003 (Kasprak, 2004).
} 
state laws providing for the medical use of marijuana" (Ogden, 2009, p. 1-2). State MMLs passed following this announcement have provided much more explicit and comprehensive state regulation and oversight of the supply chain, including oversight of cultivation, dispensaries and labeling of cannabis-derived products. ${ }^{7}$ Some states that passed early laws subsequently modified their policies after the Ogden memo, providing more explicit protection and regulation of retail dispensaries for medical marijuana (e.g., Colorado in 2010).

\subsection{Medical Marijuana Laws and Dispensaries Today}

As of December 2018, thirty-three states and the District of Columbia had medical marijuana laws in effect, and the number continues to grow each year. All of these states, except Alaska, allow for legally protected dispensaries (see Table 1 for state laws in effect through 2017). ${ }^{8}$ Only 22 out of the 29 jurisdictions with medical marijuana laws in effect in 2017 had legal dispensaries that were actually open and operating as of the end of 2017, even though every state adopting a new medical marijuana law since 2010 has included state-licensed dispensaries as a legal form of supply in the initiating legislation. The rules and regulation surrounding the licensing of retail sale and distribution of medical marijuana has become more complex and burdensome. For example, the vast majority of states today regulate dispensary density, location and product source, while nearly half also regulate stocking levels (Klieger et al., 2017). Structural requirements for dispensaries, cultivators, and processors are also imposed, with regulations related to safety and security, ventilation systems, hand washing stations, and even disposal. The development of these additional licensing requirements and regulations imposed on the cultivation, distribution and retail sale of medical marijuana have caused there to be significant lag times between the point at which a state adopts an MML allowing for dispensaries and the dispensaries actually opening, as indicated in Table 1 . This stands in stark contrast to states that adopted their initial medical marijuana law prior to 2010.

Today, legal protections provided to patients and suppliers through MMLs differ along a variety of other dimensions as well, including covered illnesses, registration requirements, cultivation allowances and rules, product safety and licensing (Klieger et al., 2017). The specific privileges and requirements related to each of these dimensions have also varied widely across states and even within states over time. This substantial heterogeneity in approaches helps to explain why studies examining the impact of simple dichotomous measures of state medical marijuana laws on various

\footnotetext{
${ }^{7}$ Newly adopted MMLs have also trended toward greater consistency with traditional medical care and pharmaceutical regulations, requiring testing and labeling of marijuana cannabinoid profiles in addition to a bona-fide clinical doctor-patient relationship requiring the ongoing management of the patient's medical condition (Williams et al., 2016).

${ }^{8}$ Alaska legalized recreational cannabis in 2014 allowing sale through retail stores for any purpose, at which point medical dispensaries would be included.
} 
outcomes at different points of time yield inconsistent and contradictory results (Anderson et al., 2013; Pacula et al., 2015; Pacula and Smart, 2017; Wen et al., 2015).

\subsection{Medical Marijuana Retail Markets and the Cost of Marijuana Use}

Medical marijuana retail markets, and MMLs more generally, influence the cost of recreational marijuana use through two broad channels: 1) reducing its monetary price by lowering the legal risk faced by now legitimate medical suppliers bringing the drug to market, which reduces their production costs (Anderson et al., 2013; Hansen et al., 2017; Sevigny et al., 2014), and 2) reducing the non-pecuniary costs associated with obtaining marijuana, including legal risks and search costs. This second point warrants further explanation of how legal protections provided to medical users might be conferred on recreational users.

In principle, MMLs that provide legal protections from state criminal prosecution for the possession and use of specified quantities of marijuana should only benefit a limited set of individuals who qualify as medical marijuana patients. ${ }^{9}$ However, these policies likely benefit recreational users as well. This is because early state laws tended to be broadly permissive in what constituted a qualifying condition, did not require a bona fide relationship between recommending physician and patient, and did not mandate that medical marijuana patients register with the state in order to receive legal protections (Mikos, 2009). ${ }^{10}$ The breadth of legal protections granted to MMLs patients without requirements for state registries make it difficult for law enforcement to differentiate medical users from recreational users. Further, the presence of medical dispensaries, whether legally protected or not, reduces the search costs associated with obtaining the product (Galenianos et al., 2012; Jacobi and Sovinsky, 2016; Pacula et al., 2010). Recent work by Sabia and Nguyen (2018) supports the conclusion that at least some of the increase in use associated wtih medical marijuana laws on adult males comes from an increase in recreational use among males under the age of 30.

The reduction in the risk associated with purchasing and using marijuana when MMLs are in place, when dispensaries are legally protected, and when they operate but without protection, is likely to vary across groups depending on the expected risks they faced under a regime of marijuana prohibition (MacCoun et al., 2009). There is a well-established literature showing that blacks and Hispanics are disproportionately arrested and convicted, particularly in cases where there is greater discretion for police in choosing suspects or for courts in determining incarceration and

\footnotetext{
${ }^{9}$ Individuals who use marijuana solely for medical purposes represent a tiny fraction of marijuana users. While $12.1 \%$ of the U.S. adult population report using marijuana for recreational purposes, only $0.8 \%$ report using marijuana for medicinal purposes only (Compton et al., 2017).

${ }^{10}$ The costs of becoming a legal medical marijuana patient include the monetary value of any patient registration fee in states that mandate registration, as well as the time costs of finding a doctor who will provide certification that the individual has a qualifying condition that could benefit from marijuana use. However, particularly when examining MMLs passed during this study's timeframe up to 2011, we anticipate these costs to be negligible.
} 
sentencing (Geller and Fagan, 2010; Goel et al., 2016; Gross and Barnes, 2002; Mustard, 2001). This has been shown specifically for marijuana possession and sales offenses (Golub et al., 2007; Nguyen and Reuter, 2012; Ramchand et al., 2006), with the most pronounced disparities for black males (Ramchand et al., 2006). ${ }^{11}$ Similarly, the impact of MMLs, operating dispensaries, and laws protecting dispensaries may also differentially impact females compared to males given experimental evidence showing females exhibit greater risk aversion and greater sensitivity to social cues than their male counterparts (Croson and Gneezy, 2009; Eckel and Grossman, 2008).

In light of these findings in the literature, we assume throughout the subsequent discussion that medical marijuana policies reduce legal risks and access costs to all potential marijuana users, both recreational and medical, allbeit to varying degrees for users from different race/ethnic groups and genders. It is this broader impact of medical marijuana policies, particularly those related to the operation and legal protection of dispensaries, on marijuana users that we seek to understand.

\section{Data}

Our analysis combines individual histories on marijuana use collected longitudinally in the National Longitudinal Survey of Youth 1997 (NLSY97) with state level information on the operating of medical marijuana dispensaries, general medical marijuana laws and laws providing legal protection to medical marijuana dispensaries.

\subsection{NLSY97}

The NLSY97 is a longitudinal survey representative of American youths who were 12-16 years old as of 31 December 1996. The first wave of the survey, fielded in 1997 and 1998, collected information on 8,984 individuals (4,599 males and 4,385 females). ${ }^{12}$ Respondents were subsequently interviewed annually until wave 15 , fielded in $2011 .^{13}$ We use data from the first 15 waves of the NLSY97, with each of these waves collecting detailed information on marijuana use, including retrospective information on age at first use, which is collected in wave $1 .^{14}$ Making use of both

\footnotetext{
${ }^{11}$ Differential arrest risk by sex and race/ethnicity has also been documented in the longitudinal data used for the current study (NLSY97), with estimates showing significantly higher cumulative prevalence of arrest by age 18 and by age 23 among males relative to females, and among black males relative to whites males (Brame et al., 2014).

${ }^{12}$ Of the 8,984 originally surveyed, 6,748 composed a representative cross-sectional sample and 2,236 compose a supplement that over-sampled Hispanics and blacks who were born in the same time period as the representative sample. We use both in our analysis.

${ }^{13}$ The retention rate for wave 15 is $85.6 \%$. The NLSY97 data has continued beyond 2011 . However, the next wave of the survey is 2013 - two years later — and does not include questions on marijuana or illicit drug use. We therefore stop our analysis in 2011.

${ }^{14}$ The information used in this paper was reported by the youth. The only exception is parental characteristics which were reported by the youths' parents in 1997.
} 
the retrospective and annually collected data allows us to construct marijuana use histories for this large, representative sample covering the period 1990-2011. ${ }^{15}$

\subsection{Marijuana Use Histories and the Duration of Use}

Of the 8,984 interviewed in wave 1 , we observe information on whether or not marijuana is used in at least one round of the survey for 8,922 individuals (4,558 males and 4,364 females). The duration of each person's marijuana use is calculated from the age of first use and the age of last use. The age at first use is self-reported for those who report having ever used marijuana in wave 1. For individuals who do not report using in wave 1, the age at first use is based on information provided in subsequent waves on whether the respondent had used marijuana since the date of the last interview (SDLI). The age of last use is defined as the age at the survey in which the respondent last reported using marijuana. Duration of use is calculated using information on the age at which the respondent last reported marijuana use combined with the age at first use. For those individuals who are not observed to quit use, their duration of marijuana use is censored at the age at which they were last surveyed (and reported marijuana use).

\subsection{The Medical Marijuana Retail Environment}

As our interest in this paper is on the decision to quit use and previous research in the alcohol and tobacco literature demonstrate the importance of retail outlets on uptake and quitting (Chen et al., 2010; Halonen et al., 2013; Reitzel et al., 2011), we focus here on two specific aspects of state medical marijuana policy environments: operating dispensaries, measured by an indicator equal to one for states in months and years in which a dispensary system is known to operate even if it is not legally protected, and legal protection for medical marijuana dispensaries, measured by an indicator equal to one for states that legally protects dispensaries to sell marijuana to patients within the state (based on month and year of the law's effective date). In some states (CA, CO, MT and WA) dispensary systems operated in specific locations prior to any legal authorization - these are our examples of de facto markets. In other states (NM, NY, MA) these dispensary systems took years to put in place and open even after the laws providing legal protections were passed. Those states with laws explicitly allowing retail dispensaries to operate are considered de jure markets. In addition, we account for whether states have passed any medical marijuana law using a dichotomous indicator which is set equal to one in month-years when a given state has an effective policy providing legal protection to patients who use marijuana for medicinal purposes.

\footnotetext{
${ }^{15}$ The interviews are conducted using a computer-assisted personal interview instrument, administered by an interviewer with a laptop computer. The mode of interview is in person or by telephone. When interviews were conducted in person, the information on drug use was self-administered. Personal interviews constitute the bulk of data.
} 
Information on state medical marijuana laws, including legal protections of dispensaries, were collected through original legal research of state statutes and regulations conducted under a series of projects funded by the National Institute on Drug Abuse and the Robert Wood Johnston Foundation (Chriqui et al., 2002; Pacula et al., 2002, 2015). The dates at which states provided these legal protections to patients and their caregivers, as well the dates when legal protections were provided to dispensaries, are shown in Table 1. Detailed information on the process for identifying whether a state legally provides a patient access to marijuana for medicinal purposes or protects retail medical marijuana dispensaries is discussed in Powell et al. (2018). As several state policies presented in Table 1 were adopted outside of the NLSY sample period we are evaluating (1997-2011), we indicate those state policies which provide variation for identification using an asterisk.

As mentioned in Section 2, several states that adopted early medical marijuana laws did not provide explicit legal protection to dispensaries, yet dispensaries were known to operate. We identified dates for dispensaries operating in these states through an extensive web search. ${ }^{16}$ Active dates were determined as the earliest month and year in which an open dispensary was either discussed or advertised in a mainstream news outlet (e.g., local TV news agency, website or newspaper). These are reported in Table 1.

The marijuana policy variables are merged onto individual's marijuana use histories on the basis of the state in which they live. Critical to our approach is measuring the policy environment in place during the recall period over which survey respondents are deciding whether to quit marijuana use. Noting that at each survey wave, individuals report on their use of marijuana "since the last interview" as well as their current residential location, the relevant policy regime will be the regime in place just prior at the start of the survey wave's reporting period, which is the day of the "last interview."

\subsection{Measurement Issues}

A potential threat to the reliable estimation of the causal effects of operating dispensaries and laws protecting them is that of measurement error in the reporting of marijuana use. Since our analysis is based on longitudinal data which records annual information on respondents use of marijuana, the possibility that errors are made in accurately remembering this information is minimized. Similarly, the regular questioning of NLSY97 respondents regarding marijuana use from relatively early ages

\footnotetext{
${ }^{16}$ The web search targeted two primary sources: (1) webpages produced by marijuana advocacy groups either informing patients of where to get marijuana or linking to dispensary webpages, such as Weedmaps, the National Organization for the Reform of Marijuana Laws (www.norml.org), Marijuana Policy Project (www.mpp.org); and (2) key word searches of old local newspapers and weekly circulars, using terms such as "medical marijuana" and "dispensary" or "cooperative." Three separate policy analysts independently conducted these searches and then convened to discuss consistency in their findings.
} 
also insures against a failure to report experimental use. ${ }^{17}$

A second potential source of measurement error arises in matching state level information on the medical marijuana retail environment to the respondent's state of residence at each age that the respondent is at risk of quitting marijuana use. However, as we observe respondents' state of residence at each interview, we are able to capture movements across state borders, mitigating the risk of measurement error with respect to the medical marijuana retail regime faced when making decisions regarding quitting. Of course, this raises the question of whether individuals move across state borders in order to access retail marijuana markets. We examine this issue in a sensitivity analysis.

\subsection{Descriptive Statistics}

Table 2 provides information on marijuana use by gender and race/ethnicity. In terms of gender, $60 \%$ of males and $53 \%$ of females report using marijuana and amongst those who have ever used, males and females report a similar age at first use; 16.6 years for males and 16.8 for females. In addition to being more likely to report using marijuana, males are also less likely to be observed to quit use, with $65 \%$ of males quitting compared to $72 \%$ of females. Conditional on quitting, males and females quit at similar ages having used for similar durations; on average males are 20.8 years old when they quit, having used for 5.1 years and females are on average 20.9 when they quit, having used for 4.9 years.

In terms of race and ethnicity, Table 2 shows that amongst females, non-Hispanic white females are more likely to report ever using marijuana than black or Hispanic females (60\% of non-Hispanic white females compared to $44 \%$ of black and $48 \%$ of Hispanic females). Non-Hispanic white and black females are less likely to quit than Hispanic females, with $71 \%$ of non-Hispanic white and black females quitting compared to $75 \%$ of Hispanic females. Amongst those who use, black females tend to start later than non-Hispanic white and Hispanic females, and amongst those who quit Hispanic females tend to quit at younger ages. As a result, non-Hispanic white females have the longest average duration of use at 5.3 years, and black females have the shortest, at 4.3 years.

Amongst males, non-Hispanic white males and black males have similar rates of marijuana use (61 and $62 \%$ respectively), while Hispanic males are less likely to report use (57\%). Black and Hispanic males are more likely than non-Hispanic white males to quit marijuana use, with quit

\footnotetext{
${ }^{17}$ Harrison et al. (2007) investigate the validity of self-reported drug use information in a general population survey in the US by comparing the self-reports of respondents with the results of drug tests of urine specimens. For marijuana, $93 \%$ of individuals self-reported use in the past 3 days agreed with their urine sample, $5.2 \%$ of those who reported no use tested positive and $1.8 \%$ reported using and tested negative. The authors also investigates whether there were differences in truthfulness of self-reports by age, comparing 12-17 year olds with those aged 18-25. Overall, both age-groups reported their drug use accurately, with 3\% under-reporting 3 day use amongst 12-17 year olds compared to $8 \%$ under-reporting 3 day use $18-25$ year olds.
} 
rates for black and Hispanic males of 67 and $68 \%$ respectively, compared to $62 \%$ for non-Hispanic white males. Among those who ever use, Non-Hispanic white males are slightly younger than their minority peers when they start marijuana use and, among those who quit, they are slightly older when they quit. As a consequence, non-Hispanic white males tend to use for longer than minority males, with white males using for 5.3 years on average compared to 4.8 and 4.5 for black and Hispanic males, respectively.

In addition to very detailed information on marijuana use, the NLSY97 provides rich information on the respondents and the households in which they grow up that we control for in our analysis. Sample averages for the control variables for the full sample and for the sub-sample of marijuana users is shown in Appendix Table A.1 and Appendix Table A.2 respectively. These tables report the sample means for the pooled sample as well as by gender and race/ethnicity.

\subsection{Stylized facts}

\subsubsection{Quitting Marijuana Use}

Figure 1 presents graphs of the hazard rate of quitting marijuana use and the cumulative quit rate at each duration of use (measured in years) for females (left graph) and males (right graph), by race/ethnicity. The hazard of quitting marijuana use is defined as the probability of quitting use at each duration of use conditional on not having already quit. This is displayed graphically in Panel A of Figure 1. The cumulative quit rate, defined as the proportion of marijuana users who have quit use at each duration of use, is shown in the graphs in Panel B. ${ }^{18}$

There are three main points to take from Figure 1. First, the hazard of quitting has a common pattern across gender and race/ethnicity; it spikes after the first year of use, and is subsequently relatively constant. ${ }^{19}$ Second, within gender, the spike in quitting after the first year of use is greater for minorities than for non-Hispanic whites, and across gender the spike in quitting after the first year of use is greater for females than males. The final point to take from Figure 1 is that, for both females and males, the cumulative quit rate (which shows the proportion who have quit) is higher at each duration of use for minorities than for non-Hispanic whites, although the difference is greater amongst males.

\subsubsection{Medical Marijuana Dispensaries and Quitting Marijuana Use}

Table 3 shows the average rate of quitting marijuana use by whether individuals live in a state that has MMLs, operating dispensaries, or legal protection for dispensaries. This information is

\footnotetext{
${ }^{18}$ Those who have not quit when they exit the sample are considered to have a right censored duration of use.

${ }^{19}$ The spike of quitting at one year of use suggests that a large proportion of individuals experiment with marijuana for a short time only.
} 
provided for the full sample and by gender. For the full sample, and for each gender, the average quit rate is also provided by race/ethnicity (non-Hispanic white versus minorities, defined as black or Hispanic).

From Table 3 it is evident that the quit rate is generally lower in states in which the MM environment is more liberal. For example, non-Hispanic white males living in a state with operating medical marijuana dispensaries are, on average, 1.60 percentage points less likely to quit compared to non-Hispanic white males living in a state without operating dispensaries $(7.92 \%$ compared to $9.52 \%$ ), and minority males are 1.57 percentage points less likely to quit if they live in a state that provides legal protection for dispensaries compared to minority males living in a state where dispensaries are not legally protected (10.29\% compared to $11.86 \%$ ). Minority females are an exception; the quit rate of minority females is in fact higher in states with more liberal MM environments. For example, minority females living in a state with operating dispensaries are 1.95 percentage points more likely to quit, on average, compared to minority females living in a state without operating dispensaries (14.94\% compared to $12.99 \%)$.

\section{Empirical Framework}

We consider a framework in which marijuana users decide whether or not to quit at each duration of use by comparing the costs and benefits of doing so. As discussed above, medical marijuana retail markets, and related laws, impact this decision by reducing the monetary and non-pecuniary costs associated with search time and legal risk of marijuana possession and use, which together we will refer to as the total cost.

The extent to which the medical marijuana environment impacts the total cost of marijuana use may differ by gender, race or ethnicity. Minorities in general, and blacks in particular, may be more sensitive to legal protections being extended to medical marijuana dispensaries given their greater risk of arrest (Geller and Fagan, 2010; Nguyen and Reuter, 2012; Ramchand et al., 2006). Similarly, sex differences in risk aversion and sensitivity to social cues (Croson and Gneezy, 2009; Flynn et al., 1994) may also result in differential effects of the legal protection of medical marijuana dispensaries on marijuana use across gender. We investigate these potential sources of heterogeneity in our empirical analysis.

\subsection{Hazard Model for Quitting Marijuana Use}

Our baseline empirical strategy uses a difference-in-differences (DID) setup, exploiting state and time variation in the operating of retail medical marijuana dispensaries and legal protections provided to them to estimate their impact on the decision to quit use. The usual framework for doing 
so is based on an empirical model of the form

$$
y_{i t}=\delta_{s}+\gamma_{t}+\beta M M_{s t}+X_{i}^{\prime} \theta+\epsilon_{i t}
$$

where $y_{i t}$ is an indicator equal to one if individual $i$ living in state $s$ quits marijuana use in period $t, \delta_{s}$ is a vector of state fixed effects, $\gamma_{t}$ is a vector of year fixed effects, and $M M_{s t}$ is the vector of policy variables $\left(M_{1 s t}, M_{2 s t}, M_{3 s t}\right)$ where $M_{1 s t}$ is an indicator for general medical marijuana law in place, $\left(M_{2 s t}\right)$ is an indicator for operating dispensaries, and $\left(M_{3 s t}\right)$ is an indicator for laws explicitly protecting medical marijuana dispensaries. The vector of parameters of interest, $(\beta)$, identify the causal effect of retail medical marijuana markets under the parallel trends assumption. As commonly done in the literature, the validity of the parallel trends assumption can be examined using leads and lags of policy indicators. Doing so, the event study can be expressed as:

$$
y_{i t}=\delta_{s}+\gamma_{t}+\sum_{k=-m}^{M} \beta^{k} M M_{s t+k}+X_{i}^{\prime} \theta+\epsilon_{i t}
$$

Because the outcome that we are studying is the decision to quit marijuana use, and as shown in Figure 1, a feature of quitting behaviour is that it exhibits duration dependence (and duration of use may be censored), we adapt the standard DID framework to a duration setting (Bartik and Nelson, 2017; Williams and Bretteville-Jensen, 2014). To do so, we embed the DID setup of equation 1 into a proportional hazard model. However, as our analysis is based on a discrete time measure of marijuana use (measured at each survey wave), we follow (Bartik and Nelson, 2017; Williams and Bretteville-Jensen, 2014) who adopt the discrete time analogue of the proportional hazard model, given by the complementary log-log hazard (clog-log), which has the following form: ${ }^{20}$

$$
\ln \left(-\ln \left(1-h_{i t}(j)\right)\right)=\alpha_{j}+\delta_{s}+\gamma_{t}+\beta M M_{s t}+X_{i}^{\prime} \theta
$$

where the hazard $h_{i t}(j)$ characterizes the probability that person $i$ at time $t$ quits marijuana use at duration of use $j$ given that they have not quit use at duration $j-1$, and $\alpha_{j}$ represents duration dependence, which is modelled non-parametrically. ${ }^{21}$

The interpretation of the (exponentiated) coefficients is in terms of hazard ratios and the analog to the linear model's difference-in-difference is the ratio of (hazard) ratios. For example, the coefficient on the indicator for state $s$ having a law protecting dispensaries in year $t$ is interpreted

\footnotetext{
${ }^{20}$ In effect, it estimates a continuous time proportional hazard model using data that is grouped into discrete intervals.

${ }^{21}$ Duration dependence is modelled as a step function, with indicators for durations of use of two years, three years, etc up to 18 or more years of use. One year of use is the base category.
} 
as the percentage change in the hazard of quitting marijuana use associated with a state adopting legal protections for medical marijuana dispensaries between period $t-1$ and time period $t$, relative to the change that occurs over the same period of time in a state which remains dispensary free. This is measured by $\left(\exp \left(\beta_{3}\right)-1\right) * 100$, where $\beta_{3}$ is the coefficient on the indicator for the state having a law protecting medical marijuana dispensaries.

In order for the vector of parameters, $\beta$ is be interpreted as the causal impact of the medical marijuana retail environment on the hazard of quitting, the equivalent of the parallel trends assumption from equation 1 must hold. The analogous assumption for our setting is that log continuous-time quitting hazards evolved along parallel trends in states that did and did not have operating or protected dispensaries (see Bartik and Nelson (2017)). To investigate this assumption, we estimate event-time versions of our hazard model specifications by including lags and leads of the policy variables, akin to the standard event study framework shown in equation 2. For example, the duration model version of equation 2 is:

$$
\ln \left(-\ln \left(1-h_{i t}(j)\right)\right)=\alpha_{j}+\delta_{s}+\gamma_{t}+\sum_{k=-m}^{M} \beta^{k} M M_{s t+k}+X_{i}^{\prime} \theta
$$

The interpretation of the event-time coefficient $\beta_{3}^{k}$, for example, is the ratio of the change in the hazard of quitting in states with legal protection for dispensaries in the kth period after (or before for $k<0$ ) their law came into effect relative to states that do not provide legal protection for medical marijuana dispensaries.

The empirical setup presented above assumes that the effect of the medical marijuana retail variables on the decision to quit marijuana use do not vary by individual characteristics. We relax this assumption to allow for differences across gender by estimating the hazard model for quitting separately over subsamples of females and males. We also wish to allow for differences within gender across race/ethnicity. In order to maintain reasonable sample sizes for estimation, we allow for differences for non-Hispanic whites and minorities (for both males and females) by interacting the vector of state policy variables, $M M_{s t}$, the state and year indicators, and all controls in $X_{i s t}$ with separate indicators for race/ethnicity is non-Hispanic white and race/ethnicity is minority (black or Hispanic). We extend this approach to allow for differences for blacks and Hispanics separately in our extended robustness analysis. All models are estimated using maximum likelihood, and we report standard errors that are clustered at the state level. 


\section{Results}

\subsection{Baseline Results}

Table 4 reports maximum likelihood coefficient estimates from the baseline DID model for quitting marijuana use. We report specifications estimated over the full sample in column 1, and over the female and male subsamples in columns 2 and 3, respectively. Panel A reports estimates for specifications that assume homogeneous treatment effects with respect to race/ethnicity. In panel $\mathrm{B}$, we relax this assumption, allowing for the treatment effect for non-Hispanic whites to differ from the treatment effect for minorities (defined as Hispanics and blacks). ${ }^{22}$

As can be seen from Panel A of Table 4, the DID estimates based on the pooled sample of females and males and assuming homogenous policy effects across non-Hispanic whites and minorities provides no evidence that MMLs, operating dispensaries or laws protecting them impact on the decision to quit marijuana use. However, the results from estimating this specification for females and males separately suggest that there are differences across gender in the impact of the policy environment on quitting marijuana use. While we are unable to detect any statistically significant impact on females' decision to quit use in response to any of the medical marijuana policy variables, including the presence or legal protection of medical marijuana dispensaries, the same is not true of males. We find that living in a state with operating retail medical marijuana dispensaries reduces the hazard of quitting marijuana use amongst males by $20 \%$ (exp(-0.22)-1). And while not reaching statistical significance at conventional levels, the presence of laws protecting medical marijuana dispensaries is estimated to reduce the hazard of quitting marijuana use of males by $10 \%$ ( $p$-value $=0.16)$. We find that living in a state in which dispensaries are both active and protected reduces the likelihood of males quitting marijuana use by $28 \%$ at each duration of use, and this effect is statistically significant $(p$-value $=0.003)$. The different findings for males and females are not surprising in light of previous studies that find gender differences in the responsiveness of substance use to changes in the policy environment (Nelson, 2014; Wen et al., 2015).

Panel B of Table 4 demonstrates that imposing a homogeneous response across race/ethnicity to the medical marijuana policy environment can also mask important differences between nonHispanic whites and minorities. Specifically we find that living is a state with operating dispensaries reduces the hazard of quitting marijuana of non-Hispanic white males by around $28 \%$ $(=\exp (-0.33-1))$. While we we find no evidence that non-Hispanic white males' decision to quit marijuana use is impacted by living in a state that provides legal protection to medical marijuana dispensaries, living in a state with a general MML increases their quit rate. Noting that states with

\footnotetext{
${ }^{22}$ Note that the DID specification in panel B includes state by race/ethnicity, year by race/ethnicity, and demographic controls by race/ethnicity interaction terms.
} 
operating dispensaries also have general MMLs, we find no net effect of living in a state with both an MML and operating dispensaries for non-Hispanic white males ( $p$-value $=0.90)$. This is because the decrease in quitting in response to operating dispensaries is offset by an increase in quitting in response to general MMLs by non-Hispanic white males.

In contrast to their non-Hispanic white peers, living in a state that provides legal protection to medical marijuana dispensaries reduces the quit rate of minority men. The point estimate implies a $21 \%$ reduction in quitting following legal protection for dispensaries coming into effect relative to living is a state where they remain unprotected. ${ }^{23}$ We also find that both living in a state with a general MML and living in a state with operating dispensaries reduces the quit rate of minority men (by 14 and 16\%, respectively), although each of these effects is imprecisely estimated. In the case of operating dispensaries, the impact for minority men is not statistically different from the impact on non-Hispanic white men $(p$-value $=0.63)$, which is estimated to reduce quitting by $28 \%$.

Overall, we conclude that while we find no robust evidence that the medical marijuana policy environment impacts on quitting behavior of females, there is evidence of significant effects for males and these effects differ across racial/ethnic groups. While we find no evidence that legal protection of medical marijuana dispensaries impacts on the quit rate of non-Hispanic white males, general MMLs and operating dispensaries having offsetting effects for this group of males. In contrast, we find that minority men are less likely to quit marijuana use when they live is a state with laws that legally protect dispensaries, and weaker evidence suggests that this group may also reduce quitting in response to operating dispensaries.

\subsection{Robustness}

The interpretation of the DID estimator as providing causal estimates of the impact of the policy variables on the decision to quit marijuana use relies on the parallel trends assumption. In order to investigate this assumption, we conduct an event study analysis which involves including leads and lags of the policy variables in the hazard model, as described in section 4.1. Evidence of an impact of the policy variables in years preceding their introduction suggests differing trends in treatment and controls states in the pre-treatment period, which is inconsistent with the parallel trends assumption.

We present the results from the event study analysis in graphical form for males in Figure $2 .{ }^{24}$ Panel A shows the results from the analysis for non-Hispanic white males and panel B shows the

\footnotetext{
${ }^{23}$ As shown in the bottom of Table 4 , the effect for minority males is statistically different from the null effect for non-Hispanic white males.

${ }^{24}$ We have also conducted the event time analysis for females. The analysis found no evidence of differing pre-trends for females in general, nor for non-Hispanic white females, nor minority females. These results are not reported here as there are no robust policy impacts found for females. These results from the event time analysis for females are available upon request.
} 
results for minority males. Each panel contains three graphs; one for each policy variable. Each graph shows a plot of the coefficient estimates (and their $95 \%$ confidence intervals) corresponding for the leads and lags of the policy variable. The coefficients are normalized to zero at the first full year that the policy is in effect.

Looking down the first column of graphs reveals no evidence of a significant pre-trend in the coefficients on general medical marijuana laws for non-Hispanic white males. For minority males, there is some evidence that quit rate is lower in the year before medical marijuana laws are introduced than in the first year they are in effect. Looking down the second column of graphs, we find no evidence of pre-trends in the coefficients on operating dispensaries for either non-Hispanic white males or minority males. Finally, the third column graphs leads and lags for laws providing protection for dispensaries. While it provides no evidence of pre-trends for non-Hispanic white males, there is some evidence that the quit rate was lower among minority males in states that introduced laws protecting dispensaries at $\mathrm{t}=-2$, corresponding to 2 or more full years before the law became effective. However, there is no difference in the quit rates between minority men living in states that do not introduce laws to protect medical marijuana dispensaries and states that do at $\mathrm{t}=-1$, corresponding to the year before the policy is introduced.

To further probe the issue of identification in our DID model, we include state and race/ethnicity specific linear trends in our baseline specification. The results from estimating this model over the subsample of males are reported in column 2 of Table 5. Column 1 repeats the baseline results from Table 4 column 3 for ease of reference. As can be seen from Table 5, including state and race specific time trends has little impact on the estimated impact of the medical marijuana policy variables for white males, and strengthens the estimated impact for minorities. This provides some reassurance that the baseline estimates can be interpreted as causal.

The third column of Table 5 investigates the extent to which our findings reflect endogenous sorting by marijuana users into states that have operating medical marijuana dispensaries, or laws to protect them. We examine this issue by removing from our sample individuals from the time they move to a state with a operating dispensaries, or laws in effect that protect them. ${ }^{25}$ As can be seen from Table 5, column 3, removing observations on individuals who are potentially sorting into states with retail markets for medical marijuana reduces the magnitude of the point estimates on operating dispensaries for non-Hispanic whites and protected dispensaries for minorities, with the former loosing statistical significance at conventional levels ( $p$-value of 0.11). Nonetheless our findings are not qualitatively changed, leading us to conclude that our results are not entirely

\footnotetext{
${ }^{25}$ Many of these individuals subsequently move out of these states, but all durations of use are dropped once an individual moves to a state with a liberal dispensary regime. We do not exclude people who move out of a state with a liberal dispensary regime and back the following wave, as this circulatory internal migration in likely to be driven by factors other than marijuana dispensaries and related policies.
} 
explained by endogenous sorting.

The final column of Table 5 attempts to tease out the separate impacts of the medical marijuana measures on Hispanic and black men. To do this, we replace the non-white interaction terms with separate interaction terms with an indicator for race is black, and interaction terms with ethnicity is Hispanic. This is quite taxing for the data given the relatively limited information on minorities in the NLSY97. Nonetheless, the results reveal a significant difference in the behavioural response of Hispanic and black men to the medical marijuana environment. Specifically, the estimates indicate that Hispanic men, but not black men, respond to operating dispensaries in their state of residence by reducing their quit rate, as do non-Hispanic white men. We note that although the impact of legal protection for dispensaries for Hispanic men is imprecisely estimated, it is not significantly different from the statistically significant impact for black males, as shown in the bottom panel of Table 5 .

\subsection{Discussion}

The significant differences across gender and race/ethnicity on quitting marijuana arising from these policies raises the question, "By how much is the duration of marijuana use extended by the presence and legal protection of dispensaries?" We now turn to answering this question.

In order to quantify the impact of operating medical marijuana dispensaries and their legal protection on quitting, we conduct simulations using the parameter estimates from Table 5, in which the policy variables are permitted to have differing effects for blacks, Hispanics, and nonHispanic whites. Because we find robust evidence that quitting behavior of males, but not females, is impacted by the presence and protection of medical marijuana dispensaries, we conduct simulations for males only. The simulations show the cumulative probability of quitting marijuana after each year of use for non-Hispanic white males in the first panel, for black males in the second panel, and for Hispanic males in the third panel. In each panel, the solid line depicts the evolution of the cumulative probability of quitting in the absence of MMLs, operating dispensaries and laws protecting them, and the dashed line shows the evolution on the cumulative probability of quitting when MMLs, operating dispensaries and laws protecting them are all in place.

As is clear from Figure 3, the proportion of non-Hispanic white male marijuana users who have quit is the same at all durations of use under either policy scenario. This is because the reduction in quitting that occurs in response to operating dispensaries is offset by an increase in quitting in response to generic MMLS, and because this group does not change their quitting behaviour in response to laws protecting medical marijuana dispensaries (and the coefficient on this variable for non-Hispanic white males is small, in addition to being statistically insignificant). ${ }^{26}$

\footnotetext{
${ }^{26}$ After 1 year of use, $26.5 \%$ of non-Hispanic white males marijuana users have quit use. The median duration of
} 
Black males and Hispanic males reduce their quit rate in response to lower perceived legal risks associated with laws protecting dispensaries, and greater access provided by operating dispensaries. This is demonstrated in the second and third panels of Figure 3, which shows a lower cumulative quit rate at each duration of use for Hispanic and black males under the scenario in which all medical marijuana policies are in effect compared to the scenario in which none are in effect. The second panel shows that the proportion of black males who have quit after one year of use is around $37 \%$ in the scenario in which there is no MML in place, no operating dispensaries and no laws protecting dispensaries, compared to $19 \%$ in the scenario in which a MML is in effect, and dispensaries are operating and have legal protection. The median duration of use of 3 years for black males living under the former scenario increases to 9.5 years when all MMLs policies are in effect. For Hispanic males, 34\% quit by the first year of use under the scenario when no MML policies are in effect compared to $17.5 \%$ when all policies are in effect, and the median duration of use increases from 3.5 to 11 years.

The implications of these longer use durations is uncertain, although the literature suggests larger downstream health and social impacts (Marie and Zölitz, 2017; van Ours and Williams, 2009; Van Ours and Williams, 2011, 2012). Extending marijuana use careers through encouraging longer durations of sporadic, casual use will have meaningfully different impacts than through increased durations of chronic, heavy use; and the actual effects will most certainly depend on the potency of the products consumed, method of ingestion, and frequency of use. Researchers are just beginning to pay attention to the relevance of these aspects of use, and thus it seems too early to know the health implications of these increases in durations of use for minority males.

\section{Conclusion}

Previous work has shown that medical marijuana laws have spill-over effects on recreational markets, increasing adult recreational marijuana use, particularly among males (Sabia and Nguyen, 2018). It is unclear, however, the extent to which this increase in use is a result of decreased quitting among adult marijuana users, or an increase in uptake among this group. To shed light on this issue, we study the decision to quit, focusing on how retail medical marijuana dispensaries and laws protecting them impact quitting behavior. The presence of an operating dispensary, regardless of its legal status, may delay quitting by reducing the search time associated with finding marijuana. Legally protected dispensaries lower not just search costs, but also the monetary cost (because suppliers face lower production costs due to their own reduction in legal risk) and legal risk faced by the user. To investigate their effects on quitting, we link information on dispensaries operating marijuana use for non-Hispanic white males is 6 years. 
and legal protections of them to self-reported longitudinal data on marijuana use from the 1997 National Longitudinal Survey of Youth. Geographic and temporal variation in the presence of operating dispensaries and their legal protection serve to identify the impact of these dimensions of the legal marijuana market on quitting behavior.

Our results highlight the importance of allowing for heterogeneous effects of legal marijuana markets on measures of marijuana use by race and ethnicity. When we impose homogeneity on the impacts of the presence of retail dispensaries and of laws protecting them across gender and race/ethnicity we find no evidence that either the presence or protection of medical marijuana dispensaries impact on the decision to quit marijuana use. Allowing for heterogeneous effects reveal important differences across gender and race/ethnicity; non-Hispanic white males delay quitting in response to the presence of operating retail dispensaries suggesting they are more sensitive to the time and monetary factors. Black males respond to the legal protection of retail dispensaries but not operating dispensaries, suggesting they are more sensitive to the legal risk. Hispanic males delay quitting in response to both the legal protection and presence of operating retail medical marijuana dispensaries, suggesting they are responsive to reductions in all components of cost. We find little robust evidence that quitting by females responds to either the presence or protection of retail medical marijuana dispensaries. We conclude that the decision to quit using marijuana among men, and therefore the duration of use, is sensitive to both de facto retail markets and de jure retail markets, although racial and ethnic differences in responsiveness to each of these types of markets can mask their effects. The sensitivity by minorities to legal risks imposed by different policies is not surprising in light of their increased risk of arrest for simple marijuana offenses, particularly for black males.

Because earlier incantations of medical marijuana dispensary laws were subject to less stringent state oversight, our findings may better reflect the potential effects of recent recreational marijuana policies than the more "medicalized" MMLs passed since 2010. The relevance of these findings in light of recent state laws to legalize recreational marijuana is that they suggest such liberalization policies may help reduce the racial and ethnic disparities associated with prohibition in the United States, particularly among blacks. This could represent an important benefit of these policies that is not fully reflected in criminal justice savings. However, the results also suggest that it is important to understand quickly whether there are differential impacts of legalized markets on patterns of use by various ethnic groups. We find that de jure legalization reduces quitting and increases the duration of use amongst minority men. In the absence of further information on the frequency and intensity of use, as well as the the strength of marijuana product used, is unclear whether and to what extent this behavior will translate into differential health impacts, further exasperating health disparities amongst minority men. 


\section{References}

Anderson, D. M., B. Hansen, and D. I. Rees (2013). Medical marijuana laws, traffic fatalities, and alcohol consumption. The Journal of Law and Economics 56(2), 333-369.

Anderson, D. M., B. Hansen, and D. I. Rees (2015). Medical marijuana laws and teen marijuana use. American Law and Economics Review 17(2), 495-528.

Annas, G. J. (1997). Reefer madness: the federal response to california's medical-marijuana law. New England Journal of Medicine 337, 435-439.

Baker, D. (2007). N.M.: Won't oversee marijuana production. Associated Press, 15 August 2007. Available at: http://usatoday30.usatoday.com/news/health/2007-08-16-3815954333x.htm/.

Bartik, A. W. and S. T. Nelson (2017). Credit reports as résumés: The incidence of pre-employment credit screening. MIT Department of Economics Graduate Student Research Paper, October 29, 2017.

Bradford, A. C. and W. D. Bradford (2018). The impact of medical marijuana legalization on prescription medication use and costs in medicare part d. The Journal of Law and Economics 61, 461-487.

Brame, R., S. D. Bushway, R. Paternoster, and M. G. Turner (2014). Demographic patterns of cumulative arrest prevalence by ages 18 and 23. Crime $\mathcal{E}$ Delinquency 60(3), 471-486.

Chen, M.-J., J. W. Grube, and P. J. Gruenewald (2010). Community alcohol outlet density and underage drinking. Addiction 105(2), 270-278.

Chriqui, J. F., R. L. Pacula, D. C. McBride, D. A. Reichmann, C. J. Vanderwaal, and Y. Terry-McElrath (2002). Illicit drug policies: Selected laws from the 50 states. Andrews University Berrien Springs, MI.

Claiborne, W. (1997). Federal warning on medical marijuana leaves physicians feeling intimidated. The Washington Post, 1 January 1997. Available at: https://www . washingtonpost.com/archive/politics/ 1997/01/01/federal-warning-on-medical-marijuana-leaves-physicians-feeling-intimidated/ 6d521a3f-1e76-4c01-a0b1-7dda0abf0261/?utm_term=.aa20082b8f8e.

Compton, W. M., B. Han, A. Hughes, C. M. Jones, and C. Blanco (2017). Use of marijuana for medical purposes among adults in the United States. Jama 317(2), 209-211.

Croson, R. and U. Gneezy (2009). Gender differences in preferences. Journal of Economic literature 47(2), $448-74$.

DeCicca, P., D. Kenkel, and A. Mathios (2008). Cigarette taxes and the transition from youth to adult smoking: Smoking initiation, cessation, and participation. Journal of health economics 27(4), 904-917.

Eckel, C. C. and P. J. Grossman (2008). Men, women and risk aversion: Experimental evidence. Handbook of experimental economics results 1, 1061-1073.

Flynn, J., P. Slovic, and C. K. Mertz (1994). Gender, race, and perception of environmental health risks. Risk analysis 14(6), 1101-1108.

Galenianos, M., R. L. Pacula, and N. Persico (2012). A search-theoretic model of the retail market for illicit drugs. The Review of Economic Studies 79(3), 1239-1269.

Geller, A. and J. Fagan (2010). Pot as pretext: Marijuana, race, and the new disorder in New York City street policing. Journal of Empirical Legal Studies 7(4), 591-633.

Goel, S., J. M. Rao, R. Shroff, et al. (2016). Precinct or prejudice? Understanding racial disparities in New York City's stop-and-frisk policy. The Annals of Applied Statistics 10(1), 365-394. 
Golub, A., B. D. Johnson, and E. Dunlap (2007). The race/ethnicity disparity in misdemeanor marijuana arrests in New York City. Criminology 85 public policy 6(1), 131-164.

Gross, S. R. and K. Y. Barnes (2002). Road work: Racial profiling and drug interdiction on the highway. Michigan Law Review 101(3), 651-754.

Hall, W. (2015). What has research over the past two decades revealed about the adverse health effects of recreational cannabis use? Addiction 110(1), 19-35.

Halonen, J. I., M. Kivimäki, A. Kouvonen, J. Pentti, I. Kawachi, S. Subramanian, and J. Vahtera (2013). Proximity to a tobacco store and smoking cessation: A cohort study. Tobacco control 23, 146-151.

Hansen, B., K. Miller, and C. Weber (2017). Drug trafficking under partial prohibition: Evidence from recreational marijuana. Working Paper 23762, National Bureau of Economic Research.

Harrison, L. D., S. S. Martin, T. Enev, and D. Harrington (2007). Comparing drug testing and self-report of drug use among youths and young adults in the general population. Technical report, (DHHS Publication No. SMA 07-4249, Methodology Series M-7). Rockville, MD: Substance Abuse and Mental Health Services Administration, Office of Applied Studies.

Hasin, D. S., M. Wall, K. M. Keyes, M. Cerdá, J. Schulenberg, P. M. O’Malley, S. Galea, R. Pacula, and T. Feng (2015). Medical marijuana laws and adolescent marijuana use in the USA from 1991 to 2014: Results from annual, repeated cross-sectional surveys. The Lancet Psychiatry 2(7), 601-608.

Jacobi, L. and M. Sovinsky (2016). Marijuana on main street? Estimating demand in markets with limited access. American Economic Review 106(8), 2009-45.

Johnson, D. and N. A. Lewis (2009). Obama Administration to stop raids on medical marijuana dispensaries. The New York Times, 18 March 2009. Available at: http://www.nytimes.com/2009/03/19/us/ 19holder/.

Kasprak, J. (2004, February). Medical marijuana-federal appellate court decision. Technical Report 2004R-0200, Office of Legislative Research, Connecticut General Assembly.

Kilmer, B. and R. L. Pacula (2017). Understanding and learning from the diversification of cannabis supply laws. Addiction 112(7), 1128-1135.

Klieger, S. B., A. Gutman, L. Allen, R. L. Pacula, J. K. Ibrahim, and S. Burris (2017). Mapping medical marijuana: state laws regulating patients, product safety, supply chains and dispensaries, 2017. Addiction.

Kreit, A. (2016). Marijuana legalization and pretextual stops. UCDL Rev. 50, 741.

Law, S. A. (2001). In the name of federalism: The supreme court's assault on democracy and civil rights. U. Cin. L. Rev. 70, 367.

Lillard, D., E. Molloy, and A. Sfekas (2013). Smoking initiation and the iron law of demand. Journal of health economics 32, 114-127.

MacCoun, R., R. L. Pacula, J. Chriqui, K. Harris, and P. Reuter (2009). Do citizens know whether their state has decriminalized marijuana? Assessing the perceptual component of deterrence theory. Review of Law $\&$ Economics 5(1), 347-371.

Marie, O. and U. Zölitz (2017). "High" achievers? Cannabis access and academic performance. The Review of Economic Studies 84(3), 1210-1237.

McCaffrey, D. F., R. Liccardo Pacula, B. Han, and P. Ellickson (2010). Marijuana use and high school dropout: The influence of unobservables. Health economics 19(11), 1281-1299. 
Mikos, R. A. (2009). On the limits of supremacy: Medical marijuana and the states' overlooked power to legalize federal crime. Vand. L. Rev. 62, 1419.

Moore, T. H., S. Zammit, A. Lingford-Hughes, T. R. Barnes, P. B. Jones, M. Burke, and G. Lewis (2007). Cannabis use and risk of psychotic or affective mental health outcomes: a systematic review. The Lancet 370 (9584), 319-328.

Mustard, D. B. (2001). Racial, ethnic, and gender disparities in sentencing: Evidence from the US federal courts. The Journal of Law and Economics 44 (1), 285-314.

Nelson, J. P. (2014). Gender differences in alcohol demand: a systematic review of the role of prices and taxes. Health economics 23(10), 1260-1280.

Newbern, A. E. (2000). Good cop, bad cop: Federal prosecution of state-legalized medical marijuana use after United States v. Lopez. Cal. L. Rev. 88, 1575.

Nguyen, H. and P. Reuter (2012). How risky is marijuana possession? Considering the role of age, race, and gender. Crime 85 Delinquency 58(6), 879-910.

Nicosia, N., J. MacDonald, and R. Pacula (2017). Does mandatory diversion to drug treatment eliminate racial disparities in the incarceration of drug offenders? an examination of californias proposition 36. Journal of quantitative criminology 33, 179-205.

Ogden, D. W. (2009). Investigations and Prosecutions in States Authorizing the Medical Use of Marijuana. Memorandum for Selected United States Attorneys, U.S Department of Justice, October 19, 2009.

Pacula, R. L., J. F. Chriqui, D. A. Reichmann, and Y. M. Terry-McElrath (2002). State medical marijuana laws: Understanding the laws and their limitations. Journal of public health policy 23(4), 413-439.

Pacula, R. L., B. Kilmer, M. Grossman, and F. J. Chaloupka (2010). Risks and prices: The role of user sanctions in marijuana markets. The BE Journal of Economic Analysis 83 Policy 10(1).

Pacula, R. L., D. Powell, P. Heaton, and E. L. Sevigny (2015). Assessing the effects of medical marijuana laws on marijuana use: The devil is in the details. Journal of Policy Analysis and Management 34(1), $7-31$.

Pacula, R. L. and R. Smart (2017). Medical marijuana and marijuana legalization. Annual review of clinical psychology 13, 397-419.

Pertwee, R. G. (2014). Handbook of cannabis. Oxford University Press, USA.

Powell, D., R. L. Paula, and M. Jacobson (2018). Do medical marijuana laws reduce addictions and deaths related to pain killers? Journal of Health Economics 58, 29-42.

Ramchand, R., R. L. Pacula, and M. Y. Iguchi (2006). Racial differences in marijuana-users' risk of arrest in the United States. Drug 83 Alcohol Dependence 84(3), 264-272.

Reitzel, L. R., E. K. Cromley, Y. Li, Y. Cao, R. Dela Mater, C. A. Mazas, L. Cofta-Woerpel, P. M. Cinciripini, and D. W. Wetter (2011). The effect of tobacco outlet density and proximity on smoking cessation. American Journal of Public Health 101(2), 315-320.

Sabia, J. and T. T. Nguyen (2018). The effect of medical marijuana laws on labor market outcomes. The Journal of Law and Economics 61, 361-396.

Sevigny, E. L., R. L. Pacula, and P. Heaton (2014). The effects of medical marijuana laws on potency. International Journal of Drug Policy 25(2), 308-319. 
Smart, R. (2016). Essays on the effects of medical marijuana laws. Ph. D. thesis, UCLA.

Tiersky, M. (1998). Medical marijuana: Putting the power where it belongs. Nw. UL Rev. 93, 547.

van Ours, J. C. and J. Williams (2009). Why parents worry: Initiation into cannabis use by youth and their educational attainment. Journal of Health Economics 28, 132-142.

Van Ours, J. C. and J. Williams (2011). Cannabis use and mental health problems. Journal of Applied Econometrics 26(7), 1137-1156.

Van Ours, J. C. and J. Williams (2012). The effects of cannabis use on physical and mental health. Journal of Health Economics 31(4), 564-577.

Vickovic, S. G. (2011). Medical marijuana in the news. Southwest Journal of Criminal Justice 8(1).

Wen, H., J. Hockenberry, and J. Cummings (2015). The effect of medical marijuana laws on adolescent and adult use of marijuana. Journal of Health Economics 42, 64-80.

Williams, A. R., M. Olfson, J. H. Kim, S. S. Martins, and H. D. Kleber (2016). Older, less regulated medical marijuana programs have much greater enrollment rates than newer 'medicalized' programs. Health Affairs 35(3), 480-488.

Williams, J. and A. L. Bretteville-Jensen (2014). Does liberalizing cannabis laws increase cannabis use? Journal of health economics 36, 20-32. 
Table 1: Medical Marijuana Law (MML) Date, Legal Protection of Dispensaries, and Active Dispensaries

\begin{tabular}{|c|c|c|c|c|}
\hline & Any MML & $\begin{array}{l}\text { MML Legally } \\
\text { Protects Dispensaries }\end{array}$ & $\begin{array}{c}\text { Any } \\
\text { Dispensary }\end{array}$ & $\begin{array}{l}\text { Legally Protected } \\
\text { Dispensary }\end{array}$ \\
\hline & Date effective & Date effective & Date active & Date active \\
\hline $\mathrm{CA}$ & $11 / 6 / 1996^{*}$ & $1 / 1 / 2004^{*}$ & $11 / 10 / 1996^{*}$ & $1 / 1 / 2004^{*}$ \\
\hline OR & $12 / 3 / 1998^{*}$ & $8 / 14 / 2013$ & $11 / 13 / 2009^{*}$ & $3 / 24 / 2014$ \\
\hline WA & $12 / 3 / 1998^{*}$ & $7 / 22 / 2011^{*}$ & $10 / 1 / 2009^{*}$ & $7 / 22 / 2011^{*}$ \\
\hline $\mathrm{AK}$ & 3/4/1999* & & & \\
\hline $\mathrm{ME}$ & $12 / 23 / 1999^{*}$ & $12 / 4 / 2009^{*}$ & $3 / 31 / 2011^{*}$ & $3 / 31 / 2011^{*}$ \\
\hline HI & $6 / 14 / 2000^{*}$ & $1 / 4 / 2016$ & 8/8/2017 & 8/8/2017 \\
\hline $\mathrm{CO}$ & $12 / 28 / 2000^{*}$ & 7/1/2010* & $10 / 1 / 2005^{*}$ & 6/7/2010* \\
\hline NV & $10 / 1 / 2001^{*}$ & $7 / 1 / 2013$ & $10 / 30 / 2009 *$ & $7 / 31 / 2015$ \\
\hline MD & $10 / 1 / 2003^{*}$ & $6 / 1 / 2014$ & 7/6/2017 & $7 / 6 / 2017$ \\
\hline VT & $7 / 1 / 2004^{*}$ & $6 / 2 / 2011^{*}$ & $6 / 21 / 2013$ & $6 / 21 / 2013$ \\
\hline MT & $11 / 2 / 2004^{*}$ & $12 / 7 / 2016$ & $3 / 1 / 2009^{*}$ & $12 / 7 / 2016$ \\
\hline RI & $1 / 3 / 2006^{*}$ & $6 / 16 / 2009 *$ & $4 / 19 / 2013$ & $4 / 19 / 2013$ \\
\hline NM & $7 / 1 / 2007^{*}$ & $7 / 1 / 2007^{*}$ & $7 / 1 / 2009^{*}$ & $7 / 1 / 2009^{*}$ \\
\hline MI & $12 / 4 / 2008^{*}$ & $12 / 20 / 2016$ & $6 / 15 / 2009^{*}$ & \\
\hline NJ & $10 / 1 / 2010^{*}$ & $10 / 1 / 2010^{*}$ & $12 / 6 / 2012$ & $12 / 6 / 2012$ \\
\hline $\mathrm{DC}$ & $7 / 27 / 2010^{*}$ & $7 / 27 / 2010^{*}$ & $7 / 29 / 2013$ & $7 / 29 / 2013$ \\
\hline $\mathrm{AZ}$ & $12 / 14 / 2010^{*}$ & $12 / 14 / 2010^{*}$ & $12 / 6 / 2012$ & $12 / 6 / 2012$ \\
\hline $\mathrm{DE}$ & 7/1/2011* & 7/1/2011* & $6 / 26 / 2015$ & $6 / 26 / 2015$ \\
\hline $\mathrm{CT}$ & $10 / 1 / 2012$ & $10 / 1 / 2012$ & $8 / 20 / 2014$ & $8 / 20 / 2014$ \\
\hline MA & $1 / 1 / 2013$ & $5 / 24 / 2013$ & $6 / 24 / 2015$ & $6 / 24 / 2015$ \\
\hline $\mathrm{NH}$ & $7 / 23 / 2013$ & $7 / 23 / 2013$ & $4 / 30 / 2016$ & $4 / 30 / 2016$ \\
\hline IL & $1 / 1 / 2014$ & $1 / 1 / 2014$ & $11 / 9 / 2015$ & $11 / 9 / 2015$ \\
\hline $\mathrm{MN}$ & $5 / 30 / 2014$ & $5 / 30 / 2014$ & $7 / 1 / 2015$ & $7 / 1 / 2015$ \\
\hline NY & $7 / 5 / 2014$ & $7 / 5 / 2014$ & $1 / 7 / 2016$ & $1 / 7 / 2016$ \\
\hline PA & $5 / 17 / 2016$ & $5 / 17 / 2016$ & & \\
\hline $\mathrm{OH}$ & $9 / 8 / 2016$ & $9 / 8 / 2016$ & & \\
\hline $\mathrm{AR}$ & $11 / 9 / 2016$ & $11 / 9 / 2016$ & & \\
\hline ND & $12 / 8 / 2016$ & $12 / 8 / 2016$ & & \\
\hline FL & $1 / 3 / 2017$ & $1 / 3 / 2017$ & & \\
\hline
\end{tabular}

Notes and sources: Asterisk indicates laws or operational dates used for identification in the empirical analysis. No asterisk indicates policies adopted outside of the study period. 
Table 2: Descriptive Statistics

\begin{tabular}{lcccccccc}
\hline \hline & \multicolumn{4}{c}{ Females } & \multicolumn{4}{c}{ Males } \\
\hline & All & White & Black & Hispanic & All & White & Black & Hispanic \\
Ever use & 0.53 & 0.59 & 0.44 & 0.48 & 0.6 & 0.61 & 0.62 & 0.57 \\
Age first use & 16.8 & 16.61 & 17.52 & 16.56 & 16.59 & 16.48 & 16.8 & 16.6 \\
Quit & 0.72 & 0.71 & 0.71 & 0.75 & 0.65 & 0.62 & 0.67 & 0.68 \\
Age quit & 20.91 & 21.09 & 20.97 & 20.32 & 20.77 & 20.94 & 20.73 & 20.65 \\
Duration of use & 4.95 & 5.27 & 4.32 & 4.68 & 5.06 & 5.3 & 4.77 & 4.48 \\
\hline $\mathrm{N}$ & 2312 & 1357 & 515 & 440 & 2756 & 1487 & 713 & 556 \\
\hline \hline
\end{tabular}

Notes: Ever use is based on 8931 respondents who answered questions on marijuana use in at least one wave of the NLSY97 survey (4369 females and 4562 males). Age of first use is based on 5068 respondents who reported using marijuana in at least one survey wave. Age quit and duration of use are based on 3456 respondents who are observed to cease use (1665 females and 1791 males). $\mathrm{N}$ is the number of respondents who have ever used marijuana. 
Table 3: Quitting Marijuana use and Dispensaries

\begin{tabular}{lcccccc}
\hline \hline & \multicolumn{2}{c}{ Medical Marijuana Law } & \multicolumn{2}{c}{ Operating } & Dispensaries & \multicolumn{2}{c}{ Protected Dispensaries } \\
& No $(\%)$ & Yes $(\%)$ & No $(\%)$ & Yes (\%) & No (\%) & Yes $(\%)$ \\
\hline All & 11.24 & 10.67 & 11.14 & 10.99 & 11.15 & 10.69 \\
Non-Hispanic whites & 10.49 & 9.28 & 10.42 & 8.98 & 10.31 & 9.21 \\
Black or Hispanic & 12.35 & 12.66 & 12.28 & 13.04 & 12.43 & 12.19 \\
& & & & & & \\
Males & 10.52 & 9.66 & 10.45 & 9.73 & 10.43 & 9.22 \\
Non-Hispanic whites & 9.54 & 8.46 & 9.52 & 7.92 & 9.4 & 8.12 \\
Black or Hispanic & 11.86 & 11.28 & 11.79 & 11.52 & 11.86 & 10.29 \\
& & & & & & 12.05 \\
Females & 12.14 & 11.83 & 12.01 & 12.49 & 12.49 \\
Non-Hispanic whites & 11.59 & 10.18 & 11.45 & 10.2 & 1.35 & 10.49 \\
Black or Hispanic & 13.05 & 14.37 & 12.99 & 14.94 & 13.23 & 14.56 \\
\hline \hline
\end{tabular}

Note: The table shows the average quit rate for respondents who live in a state that does not (NO) or does have (YES) a medical marijuana law, operating dispensaries or active dispensaries. 
Figure 1: Quitting Marijuana Use

A. Hazard of Quitting Marijuana
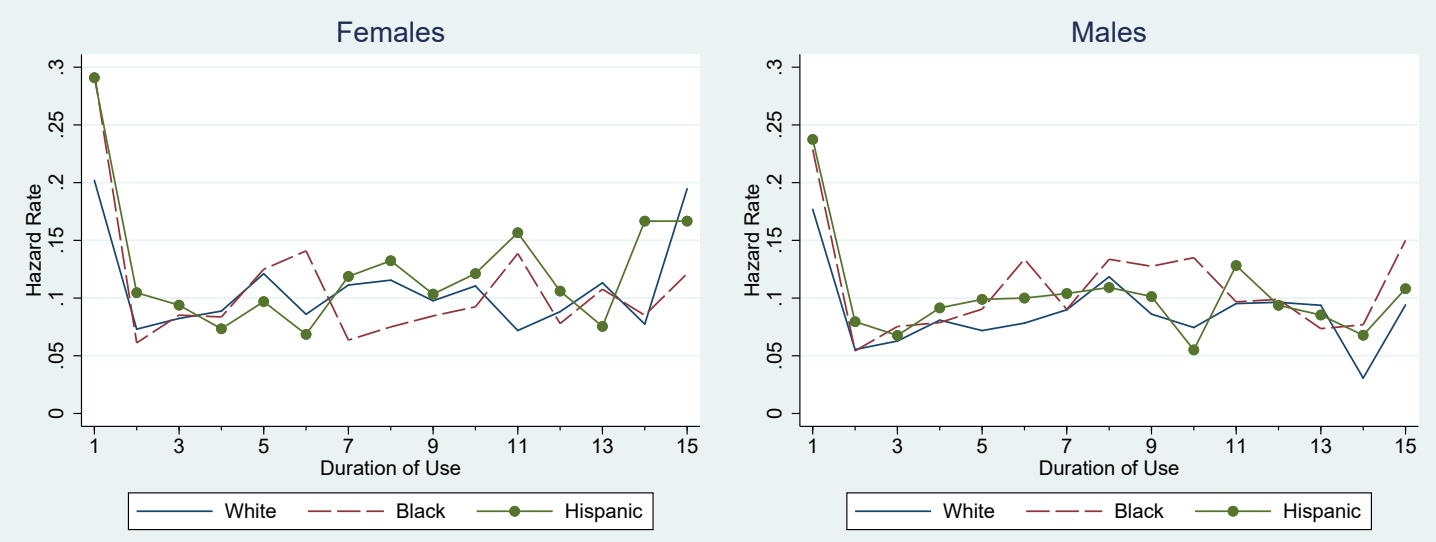

B. Cumulative Hazard of Quitting Marijuana
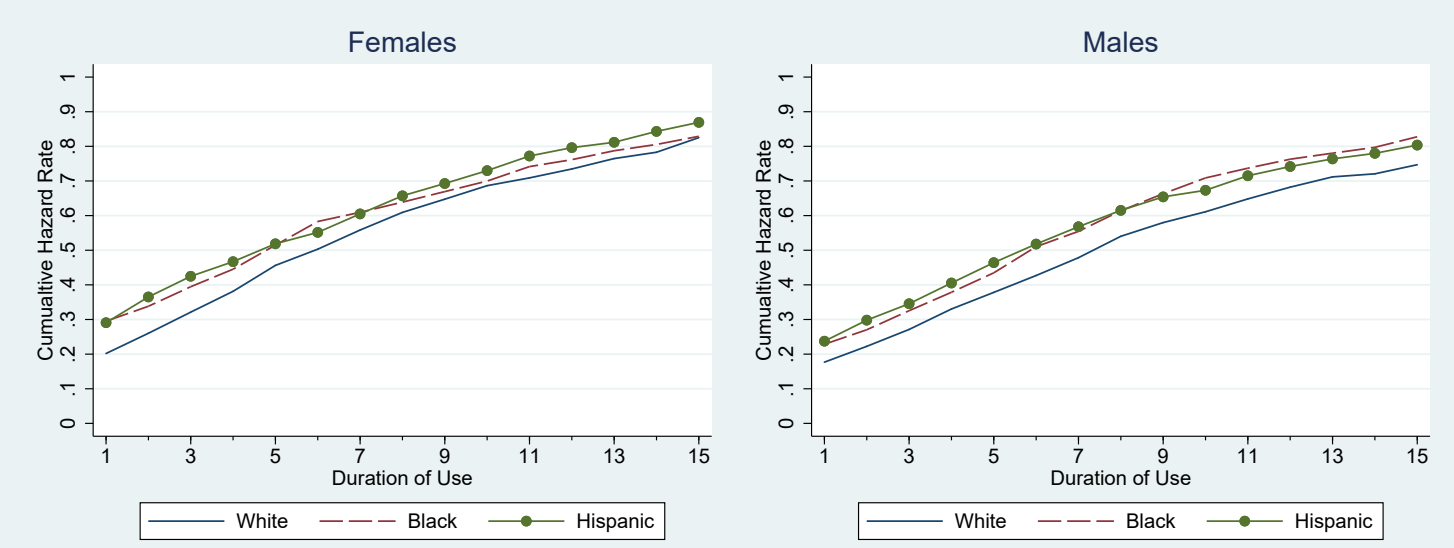
Table 4: The Impact of Dispensaries on the Hazard of Quitting Marijuana

\begin{tabular}{lccc}
\hline \hline & All & Females & Males \\
\hline A. Homogenous Policy Effects by Race $\backslash$ Ethnicity & & & \\
\hline MML & 0.06 & 0.01 & 0.15 \\
& $(0.10)$ & $(0.15)$ & $(0.10)$ \\
Operating Dispensaries & 0.00 & 0.25 & $-0.22^{* *}$ \\
& $0.13)$ & $(0.19)$ & $(0.09)$ \\
Protected Dispensaries & -0.07 & -0.06 & -0.11 \\
& $(0.09)$ & $(0.10)$ & $(0.08)$ \\
N & 30,972 & 13,802 & 17,161 \\
\hline B. Heterogenous Policy Effects by Race $\backslash$ Ethnicity & & & \\
\hline MML x 1(Non-Hispanic White) & 0.14 & -0.01 & $0.36^{* * *}$ \\
& $(0.14)$ & $(0.24)$ & $(0.12)$ \\
MML x 1(Black or Hispanic) & -0.08 & 0.02 & -0.15 \\
& $(0.11)$ & $(0.18)$ & $(0.18)$ \\
Operating Dispensaries x 1(Non-Hispanic White) & -0.14 & 0.04 & $-0.33^{*}$ \\
& $(0.18)$ & $(0.23)$ & $(0.17)$ \\
Operating Dispensaries x 1(Black or Hispanic) & $0.21^{* *}$ & $0.82^{* * *}$ & -0.17 \\
& $(0.11)$ & $(0.16)$ & $(0.21)$ \\
Protected Dispensaries x 1(Non-Hispanic White) & 0.08 & -0.02 & 0.13 \\
Protected Dispensaries x 1(Black or Hispanic) & $(0.12)$ & $(0.11)$ & $(0.14)$ \\
N-value jointly zero & -0.11 & -0.02 & $-0.24^{* * *}$ \\
Time-Race Fixed Effects & $(0.08)$ & $(0.15)$ & $(0.08)$ \\
State-Race Fixed Effects & 30,716 & 13,681 & 16,988 \\
Race-Demographic Controls & $\mathrm{Y}$ & $\mathrm{Y}$ & $\mathrm{Y}$ \\
PML & $\mathrm{Y}$ & $\mathrm{Y}$ & $\mathrm{Y}$ \\
Protected Dispensaries & $\mathrm{Y}$ & $\mathrm{Y}$ & $\mathrm{Y}$ \\
& & & \\
& & & \\
& 0.1032 & 0.0000 & 0.0002 \\
\hline
\end{tabular}

Note: Standard errors clustered at the state level in parentheses; $* * * \mathrm{p}<0.01,{ }^{* *} \mathrm{p}<0.05,{ }^{*} \mathrm{p}<0.1$. Controls include: ability (standardized CAT-ASVAB score corrected for years of schooling at the test date), indicators for year of birth, mother a teen at the respondents birth, responding parent is very religious, parents' education (of the mother and father separately), mother's parenting style is authoritarian parenting style, (log of) household income and (log of) household size, living in urban location, indicators for state of residence, indicators for calendar year. Duration dependence is modelled flexibly using a set of indicators for duration of use. 
Table 5: Robustness

\begin{tabular}{|c|c|c|c|c|}
\hline & $(1)$ & $(2)$ & $(3)$ & $(4)$ \\
\hline MML x 1(Non-Hispanic White) & $\begin{array}{c}0.36^{* * *} \\
(0.12)\end{array}$ & $\begin{array}{l}0.31^{*} \\
(0.17)\end{array}$ & $\begin{array}{c}0.36 * * * \\
(0.13)\end{array}$ & $\begin{array}{c}0.35^{* * *} \\
(0.12)\end{array}$ \\
\hline MML x 1(Black or Hispanic) & $\begin{array}{l}-0.15 \\
(0.18)\end{array}$ & $\begin{array}{c}-0.36^{*} \\
(0.19)\end{array}$ & $\begin{array}{l}-0.18 \\
(0.19)\end{array}$ & \\
\hline MML x 1(Black) & & & & $\begin{array}{l}-0.41 \\
(0.33)\end{array}$ \\
\hline MML x 1( Hispanic) & & & & $\begin{array}{c}0.05 \\
(0.27)\end{array}$ \\
\hline Operating Dispensaries x 1 (Non-Hispanic White) & $\begin{array}{c}-0.33^{*} \\
(0.17)\end{array}$ & $\begin{array}{c}-0.38^{* *} \\
(0.16)\end{array}$ & $\begin{array}{l}-0.28 \\
(0.17)\end{array}$ & $\begin{array}{c}-0.34^{* *} \\
(0.17)\end{array}$ \\
\hline Operating Dispensaries x 1(Black or Hispanic) & $\begin{array}{l}-0.17 \\
(0.21)\end{array}$ & $\begin{array}{l}-0.01 \\
(0.30)\end{array}$ & $\begin{array}{l}-0.10 \\
(0.24)\end{array}$ & \\
\hline Operating Dispensaries x 1(Black) & & & & $\begin{array}{c}0.39 \\
(0.32)\end{array}$ \\
\hline Operating Dispensaries x 1(Hispanic) & & & & $\begin{array}{c}-0.61^{* *} \\
(0.27)\end{array}$ \\
\hline Protected Dispensaries x 1(Non-Hispanic White) & $\begin{array}{c}0.13 \\
(0.14)\end{array}$ & $\begin{array}{l}-0.26 \\
(0.28)\end{array}$ & $\begin{array}{c}0.02 \\
(0.08)\end{array}$ & $\begin{array}{c}0.13 \\
(0.14)\end{array}$ \\
\hline Protected Dispensaries x 1(Black or Hispanic) & $\begin{array}{c}-0.24^{* * *} \\
(0.08)\end{array}$ & $\begin{array}{c}-0.46^{* * *} \\
(0.17)\end{array}$ & $\begin{array}{c}-0.19^{* * *} \\
(0.08)\end{array}$ & \\
\hline Protected Dispensaries x 1(Black) & & & & $\begin{array}{c}-0.76^{*} \\
(0.40)\end{array}$ \\
\hline Protected Dispensaries x 1( Hispanic) & & & & $\begin{array}{l}-0.16 \\
(0.15)\end{array}$ \\
\hline $\mathrm{N}$ & 16,988 & 16,988 & 16,470 & 16,959 \\
\hline Time-Race Fixed Effects & $\mathrm{Y}$ & $\mathrm{Y}$ & $\mathrm{Y}$ & $\mathrm{Y}$ \\
\hline State-Race Fixed Effects & $\mathrm{Y}$ & $\mathrm{Y}$ & $\mathrm{Y}$ & $\mathrm{Y}$ \\
\hline Race-Demographic Controls & $\mathrm{Y}$ & $\mathrm{Y}$ & $\mathrm{Y}$ & $\mathrm{Y}$ \\
\hline State-Race Time Trends & $\mathrm{N}$ & $\mathrm{Y}$ & $\mathrm{N}$ & $\mathrm{N}$ \\
\hline p-value for test of coefficient equality & White $=\mathrm{B}$ & ack or His & anic & Black $=$ Hispanic \\
\hline MML & 0.0151 & 0.0089 & 0.0159 & 0.3302 \\
\hline Operating Dispensaries & 0.6344 & 0.2504 & 0.6400 & 0.0415 \\
\hline Protected Dispensaries & 0.0083 & 0.4641 & 0.0423 & 0.2252 \\
\hline P-value jointly zero & 0.0002 & 0.0140 & 0.0049 & 0.0000 \\
\hline
\end{tabular}

Note: Standard errors clustered at the state level in parentheses; ${ }^{* * *} \mathrm{p}<0.01,{ }^{* *} \mathrm{p}<0.05, * \mathrm{p}<0.1$. Controls include: ability (standardized CAT-ASVAB score corrected for years of schooling at the test date), indicators for year of birth, mother a teen at the respondents birth, responding parent is very religious, parents' education (of the mother and father separately), mother's parenting style is authoritarian parenting style,(log of) household income and (log of) household size, living in urban location, indicators for state of residence, indicators for calendar year. Duration dependence is modelled flexibly using a set of indicators for duration of use. Column 3 drops individuals from the time they move to a state that has operating retail dispensaries or effective laws protecting them. 
Figure 2: Event Analysis

\section{A. Events Analysis: Non-Hispanic White Males}
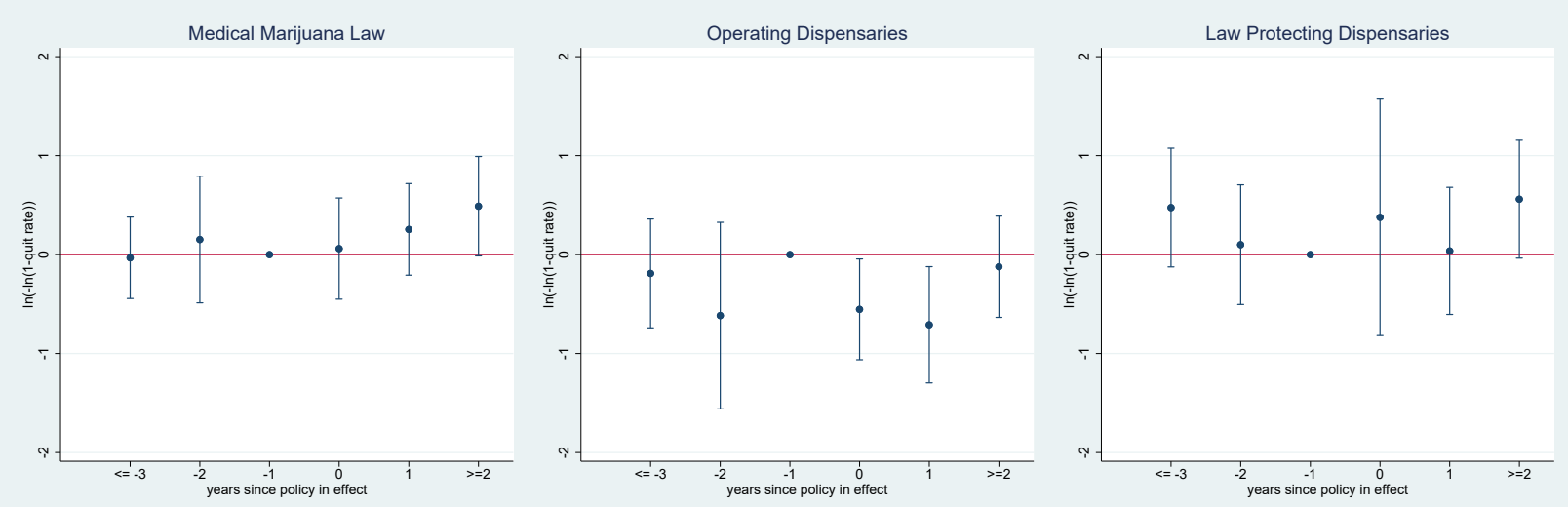

B. Events Analysis: Hispanic or Black Males
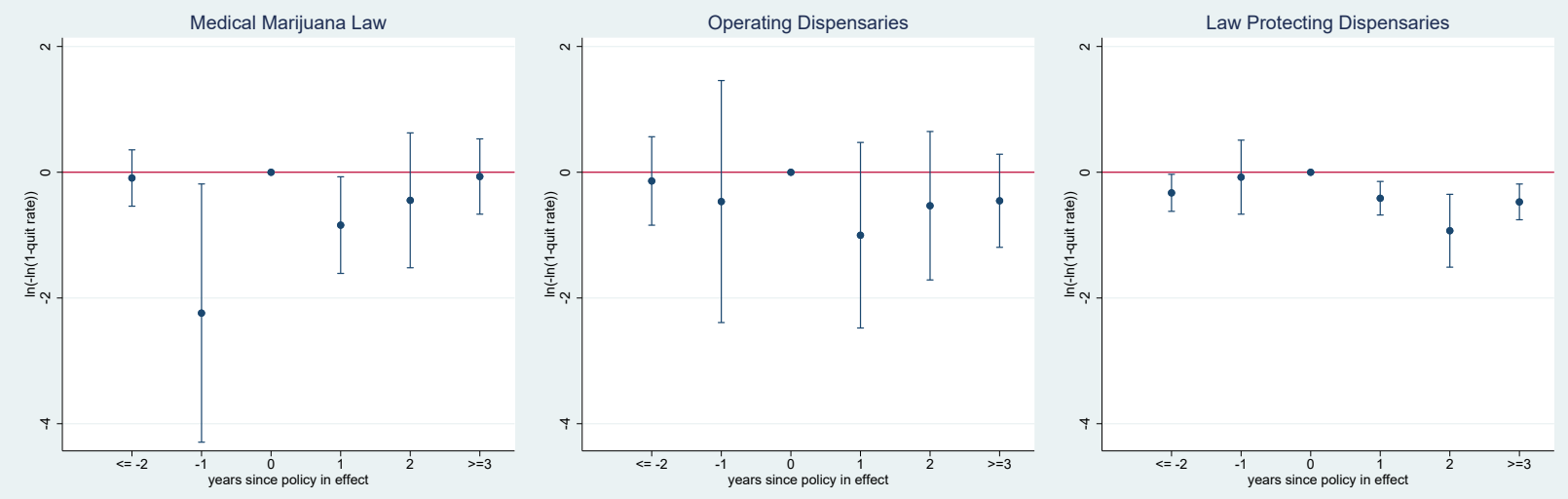

The figure shows the results of an event-time analysis of the difference on the complementary log-log of the marijuana quitting rate (ie $\ln (-\ln (1$-quitting rate $))$ ) between states that have a MML, operating dispensaries, and laws protecting dispensaries and those that do not before and after the change came into effect. The reported coefficients are from estimating a version of the baseline model (Table 4) that includes interactions between indicators for living in a state with the policy and indicators for event time. Event time is defined as the calendar year of survey minus the year that the policy came into effect. Error bars show $95 \%$ confidence intervals generated from standard errors clustered at the state level. 


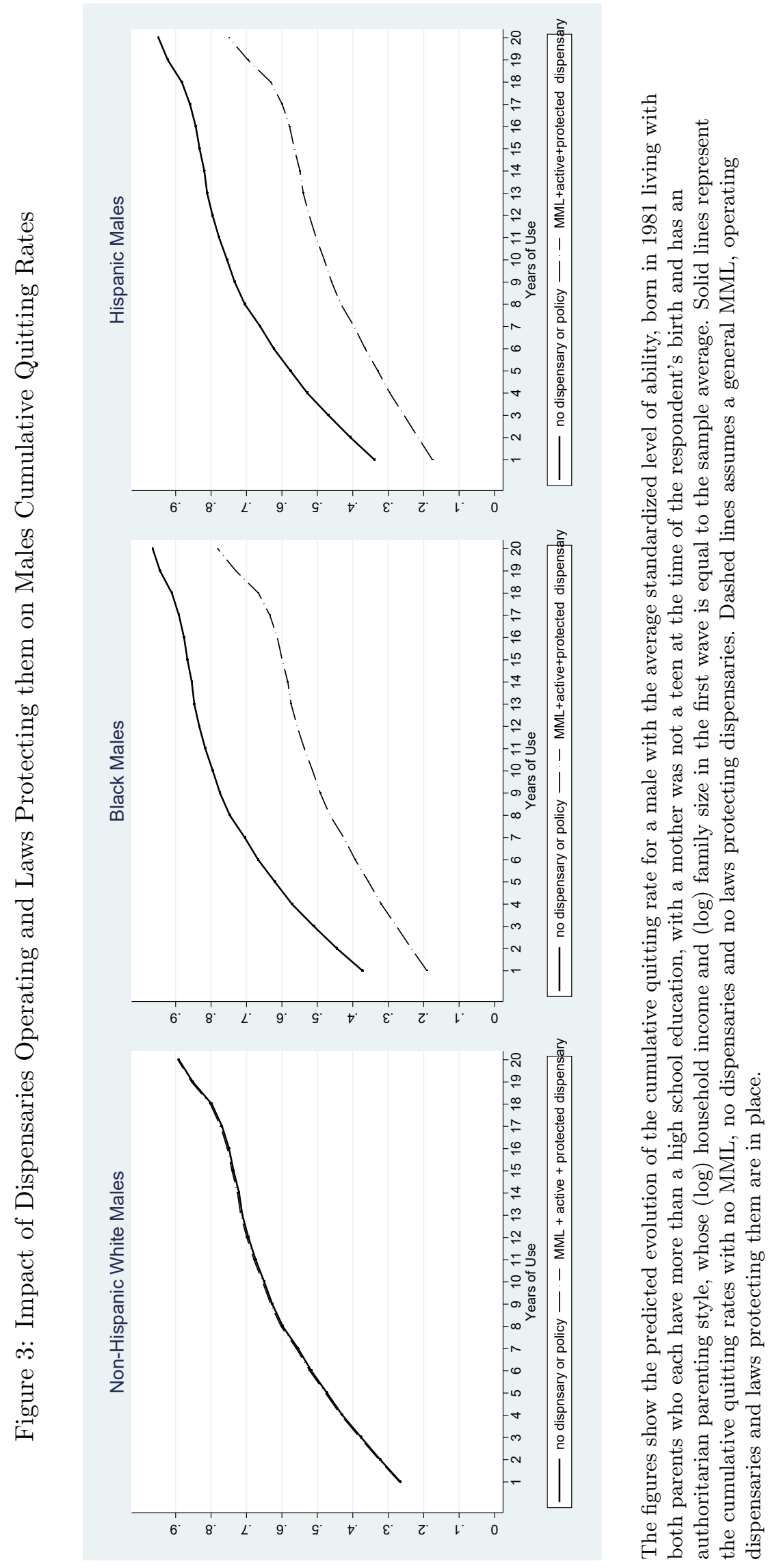


Table A.1: Descriptive Statistics on Control Variables: Full Sample

\begin{tabular}{lcccccc}
\hline & All & Females & Males & Black & Hispanic & White \\
\hline Teen mum & 0.12 & 0.13 & 0.12 & 0.19 & 0.14 & 0.09 \\
Female & 0.49 & 1.00 & 0.00 & 0.50 & 0.49 & 0.48 \\
Black & 0.26 & 0.27 & 0.25 & 1.00 & 0.00 & 0.00 \\
Hispanic & 0.21 & 0.21 & 0.21 & 0.00 & 1.00 & 0.00 \\
Stabdardized ability & 0.00 & 0.03 & -0.03 & -0.49 & -0.29 & 0.37 \\
Mom authoritarian & 0.55 & 0.54 & 0.55 & 0.60 & 0.54 & 0.52 \\
Mom present & 0.92 & 0.92 & 0.93 & 0.88 & 0.93 & 0.94 \\
Dad present & 0.67 & 0.65 & 0.69 & 0.42 & 0.67 & 0.79 \\
Parent very religious (1997) & 0.88 & 0.89 & 0.87 & 0.88 & 0.93 & 0.86 \\
Log household income & 3.51 & 3.49 & 3.54 & 3.16 & 3.19 & 3.82 \\
Log household size & 1.46 & 1.46 & 1.46 & 1.45 & 1.55 & 1.43 \\
Mom ed high school grad & 0.36 & 0.36 & 0.37 & 0.43 & 0.27 & 0.37 \\
Mom ed greater than high school grad & 0.40 & 0.39 & 0.40 & 0.32 & 0.23 & 0.50 \\
Dad ed high school grad & 0.43 & 0.44 & 0.42 & 0.61 & 0.32 & 0.39 \\
Dad ed greater than high school grad & 0.34 & 0.34 & 0.35 & 0.20 & 0.21 & 0.46 \\
\hline N & 8,931 & 4,369 & 4,562 & 2,320 & 1,891 & 4720 \\
\hline
\end{tabular}


Table A.2: Descriptive Statistics on Control Variables: Ever Used Marijuana

\begin{tabular}{lcccccc}
\hline & All & Females & Males & Black & Hispanic & White \\
\hline Teen mum & 0.12 & 0.12 & 0.12 & 0.18 & 0.13 & 0.09 \\
Female & 0.46 & 1.00 & 0.00 & 0.42 & 0.44 & 0.48 \\
Black & 0.24 & 0.22 & 0.26 & 1.00 & 0.00 & 0.00 \\
Hispanic & 0.20 & 0.19 & 0.20 & 0.00 & 1.00 & 0.00 \\
Standardized ability & 0.04 & 0.12 & -0.03 & -0.48 & -0.24 & 0.36 \\
Mom authoritarian & 0.53 & 0.51 & 0.54 & 0.60 & 0.51 & 0.50 \\
Mom present & 0.92 & 0.92 & 0.92 & 0.88 & 0.92 & 0.93 \\
Dad present & 0.66 & 0.65 & 0.67 & 0.42 & 0.65 & 0.77 \\
Parent very religious (1997) & 0.86 & 0.87 & 0.85 & 0.87 & 0.91 & 0.84 \\
Log household income & 3.54 & 3.55 & 3.54 & 3.17 & 3.23 & 3.81 \\
Log household size & 1.44 & 1.44 & 1.45 & 1.44 & 1.52 & 1.41 \\
Mom ed high school grad & 0.36 & 0.35 & 0.37 & 0.42 & 0.29 & 0.36 \\
Mom ed greater than high school grad & 0.42 & 0.44 & 0.40 & 0.33 & 0.26 & 0.51 \\
Dad ed high school grad & 0.42 & 0.42 & 0.42 & 0.58 & 0.35 & 0.37 \\
Dad ed greater than high school grad & 0.35 & 0.36 & 0.35 & 0.21 & 0.21 & 0.47 \\
\hline N & 5,068 & 2,312 & 2,756 & 1,228 & 996 & 2,844 \\
\hline
\end{tabular}

